This item was submitted to Loughborough's Research Repository by the author.

Items in Figshare are protected by copyright, with all rights reserved, unless otherwise indicated.

\title{
Interaction of metastable zone width and induction time based on nucleation potential
}

PLEASE CITE THE PUBLISHED VERSION

https://doi.org/10.1021/acs.iecr.0c04742

\section{PUBLISHER}

American Chemical Society

VERSION

AM (Accepted Manuscript)

\section{PUBLISHER STATEMENT}

This document is the Accepted Manuscript version of a Published Work that appeared in final form in Industrial and Engineering Chemistry Research, copyright $@$ American Chemical Society after peer review and technical editing by the publisher. To access the final edited and published work see https://doi.org/10.1021/acs.iecr.0c04742

\section{LICENCE}

CC BY-NC-ND 4.0

\section{REPOSITORY RECORD}

Si, Zehao, Ang Li, YiZhen Yan, Xiangyang Zhang, and Huaiyu Yang. 2020. "Interaction of Metastable Zone Width and Induction Time Based on Nucleation Potential”. Loughborough University. https://hdl.handle.net/2134/16803682.v1. 
This document is confidential and is proprietary to the American Chemical Society and its authors. Do not copy or disclose without written permission. If you have received this item in error, notify the sender and delete all copies.

\section{Interaction of Metastable Zone Width and Induction Time based on Nucleation Potential}

\begin{tabular}{|r|l|}
\hline Journal: & Industrial \& Engineering Chemistry Research \\
\hline Manuscript ID & ie-2020-04742p \\
\hline Manuscript Type: & Article \\
\hline Complete List of Authors: & $\begin{array}{l}\text { Si, Zehao; East China University of Science and Technology } \\
\text { Li, Ang; East China University of Science and Technology } \\
\text { Yan, Yizhen; East China University of Science and Technology } \\
\text { Zhang, Xiangyang; East China University of Science and Technology } \\
\text { Yang, Huaiyu; Loughborough University Department of Chemical } \\
\text { Engineering }\end{array}$ \\
\hline
\end{tabular}

\section{SCHOLARONE" Manuscripts}




\title{
Interaction of Metastable Zone Width and Induction
}

\section{Time based on Nucleation Potential}

\author{
Zehao Sia , Ang Lia, YiZhen Yana, Xiangyang Zhanga, ${ }^{\text {, }}$, Huaiyu Yang ${ }^{\text {, }}{ }^{*}$ \\ a State Key Laboratory of Chemical Engineering, East China University of Science \\ and Technology, Shanghai 200237, China \\ b Department of Chemical Engineering, Loughborough University, Loughborough \\ LE11 3TU, UK
}

\begin{abstract}
The induction times at supersaturation of $1.15-1.24$ and the metastable zone widths with cooling rates of $6.0-30.0 \mathrm{~K} / \mathrm{h}$ have been determined in the system of dicyandiamide and water. A model based on accumulation of nucleation potential, derived from the classical nucleation theory, has been applied to estimate the critical nucleation potential and pre-exponential factor for both experimental results of induction times and metastable zone widths. The estimation values were fairly agreed with the experimental values. The preexponential factor was assumed to be constant in the model, while the modifications of pre-exponential factor, dependent on the supersaturation, has been introduced to the model, for a more consistent estimations between the induction time and metastable zone width.
\end{abstract}

Keywords: Nucleation potential, Pre-exponential factor, Induction time, Metastable zone width, Dicyandiamide 


\section{Introduction}

The nucleation occurs everywhere in nature, including clouds, snow, rainfall, and volcanic eruptions ${ }^{[1]}$. Industry crystallization is a key step for the manufacturing of pharmaceuticals. Nucleation, as the first step of the crystallization, determines the polymorph and particle attributions such as size distribution of the products ${ }^{[2,3]}$. Due to the energy barrier, nucleation not always happens when the system becomes supersaturated, i.e. the temperature of the solution decreases below the saturated temperature in a cooling crystallization. While the nucleation occurs until the solution passes a metastable zone width, MSZW, below the solubility on the phase diagram during the cooling ${ }^{[4]}$. The MSZW is the temperature difference between the saturated temperature with the temperature when nucleation occurs, which is influenced by the kinetics, such as stirring rate and cooling rate ${ }^{[5]}$.

Classic Nucleation Theory $(\mathrm{CNT})^{[6-8]}$ is still the most popular theory ${ }^{[9]}$, while some new theories, such as two-step nucleation ${ }^{[10,11]}$ and the non-classical nucleation theory ${ }^{[12,13]}$ have also been developed. The CNT is successfully used to describe how the nucleation occurs under driving force and to estimate the thermodynamic and kinetic parameters from the nucleation process. Primary nucleation mechanism has been usually studied by the polythermal and isothermal process. The supersaturation maintains the same in isothermal process experiments for determining the induction time, while the supersaturation gradually increases during the polythermal process for determining the MSZW [14-16]. There are a few models to correlate the induction time and MSZW'[17], such as models by Kubota[ ${ }^{[18]}$ for solutions seeded from outside, and by Shiau[19,20] for integrating the accumulated crystals. In the previous work ${ }^{[21,22]}$, we developed a new model based on the classic nucleation theory to correlate induction time and MSZW, which shows good consistency between the estimation value and 
the experimental values for reported systems.

Dicyandiamide $\left(\mathrm{C}_{2} \mathrm{H}_{4} \mathrm{~N}_{4}\right)$ is a nitrile derived from guanidine, molecular weight 84.08 and molecular volume $9.52 \times 10^{-29} \mathrm{~m}^{3}$, and only one polymorph reported ${ }^{[23]}$. It is widely used as a slow fertilizer ${ }^{[24,25]}$. Moreover, it has been an efficient additive for improving material performance for further application ${ }^{[26,27]}$, which requires higher dicyandiamide product quality. In industrial manufacturing, designing the appropriate crystallization process is important to keep high-quality and purity of dicyandiamide. It allows saving of the time and cost if it is possible to estimate MSZW for a better seeding time from some induction time experiments by this model. On the other side, the interfacial energy estimated from MSZW can further the understanding of the crystallization of the dicyandiamide system.

In this work, the system of dicyandiamide in the water with a saturated temperature of $293.15 \mathrm{~K}$ was used to determine the induction time at a temperature ranging from $290.15-288.15 \mathrm{~K}$ and the metastable zone width with cooling rates of $6.0-30.0 \mathrm{~K} / \mathrm{h}$. The nucleation potential model will be applied to link the MSZW and induction time of dicyandiamide in the water. We demonstrated the accumulations of nucleation potential in isothermal and polythermal process. The pre-exponential factor was estimated to be constant in this model, while in this work we have correlated the pre-exponential factor with supersaturation. The pre-exponential factor in the model will be modified to find a better agreement between the estimation values and the experimental values.

\section{Theory}

\section{Classic Nucleation Theory}

In $\mathrm{CNT}^{[28-30]}$, nucleation rate, $J(/ \mathrm{s})$ is described as 


$$
J=A \exp \left(-\frac{\Delta G^{*}}{R T}\right)=A \exp \left(-\frac{16 \pi \sigma^{3} v_{m}^{2}}{3 R^{3} T^{3}(\ln S)^{2}}\right)
$$

where $A$ is the pre-exponential factor, with unit of $/ \mathrm{s} . R$ is the ideal gas constant. $T$ is nucleation temperature, with unit of $K . \Delta G^{*}$ is the critical free energy, with unit of $\mathrm{J} / \mathrm{mol}$, which is derived by the radius of critical nucleus, $r_{\mathrm{c}}$, with unit of $\mathrm{m}$, as shown in Eqn. (2).

$$
\mathrm{r}_{\mathrm{c}}=\frac{2 v_{m} \sigma}{\Delta \mu}=\frac{2 v_{m} \sigma}{R T \ln S}
$$

$\sigma$ is the interfacial energy, with unit of $\mathrm{J} / \mathrm{m}^{2} . v_{m}$ is the molar volume of the solute, with unit of $\mathrm{m}^{3} / \mathrm{mol}$. $S$ is the supersaturation calculated as the ratio between the molar solubility $x_{0}$ at saturated temperature and solubility $x$ at the experimental temperature.

$$
\ln S=\ln \frac{x_{0}}{x}
$$

when the relax time and growth time is neglectable ${ }^{[5]}$, the nucleation rate of solution with a volume of $\mathrm{V}$ is inversely related to induction time, $J V=1 / t_{\text {ind }}$, combining Eqn 1, it can be rewritten as:[31]

$$
\ln t_{i n d}=-\ln A V+\frac{16 \pi \sigma^{3} v_{m}^{2}}{3 R^{3} T^{3}(\ln S)^{2}}=-\ln A V+\frac{\mathrm{B}}{T^{3}(\ln S)^{2}}
$$

Experimental induction time results are usually evaluated by plotting $\ln t_{\text {ind }}$ versus $T^{-3}(\ln S)^{-2}$, which determine pre-exponential $A$ and the solid-liquid interfacial free energy $\sigma$, from the slope, $B$, of the correlated linear line,

$$
\begin{gathered}
B=\frac{16 \pi \sigma^{3} v_{m}^{2}}{3 R^{3}} \\
\sigma=\left(\frac{3 R^{3} B}{16 \pi v_{m}^{2}}\right)^{\frac{1}{3}}
\end{gathered}
$$

\section{Nucleation Potential}

Eqn. (7) can be directly derived from Eqn (4): 


$$
f(S) \cdot f(t)=3 R^{3} T^{3}(\ln S)^{2} \cdot \ln \left(A V t_{\text {ind }}\right)=16 \pi \sigma^{3} v_{m}^{2}=N^{*}
$$

and there are a supersaturation-dependent function $f(S)=3 R^{3} T^{3}(\ln S)^{2}$ and a time-dependent function $f(t)=\ln \left(A V t_{\text {ind }}\right)$ in the left side, and in the right side, $N^{*}$ equal to $16 \pi \sigma^{3} \mathrm{v}^{2}$, with unit of $\mathrm{kJ}^{3} / \mathrm{mol}^{3}$, and the critical nucleation potential $N$ is one third order of $N^{*}$, with unit of $\mathrm{kJ} / \mathrm{mol}$, making a consistent unit with the energy. $N^{*}$ are a constant parameter for one system ${ }^{[21,22]}$, related to the solid-liquid interfacial energy of the solute in the solvent.

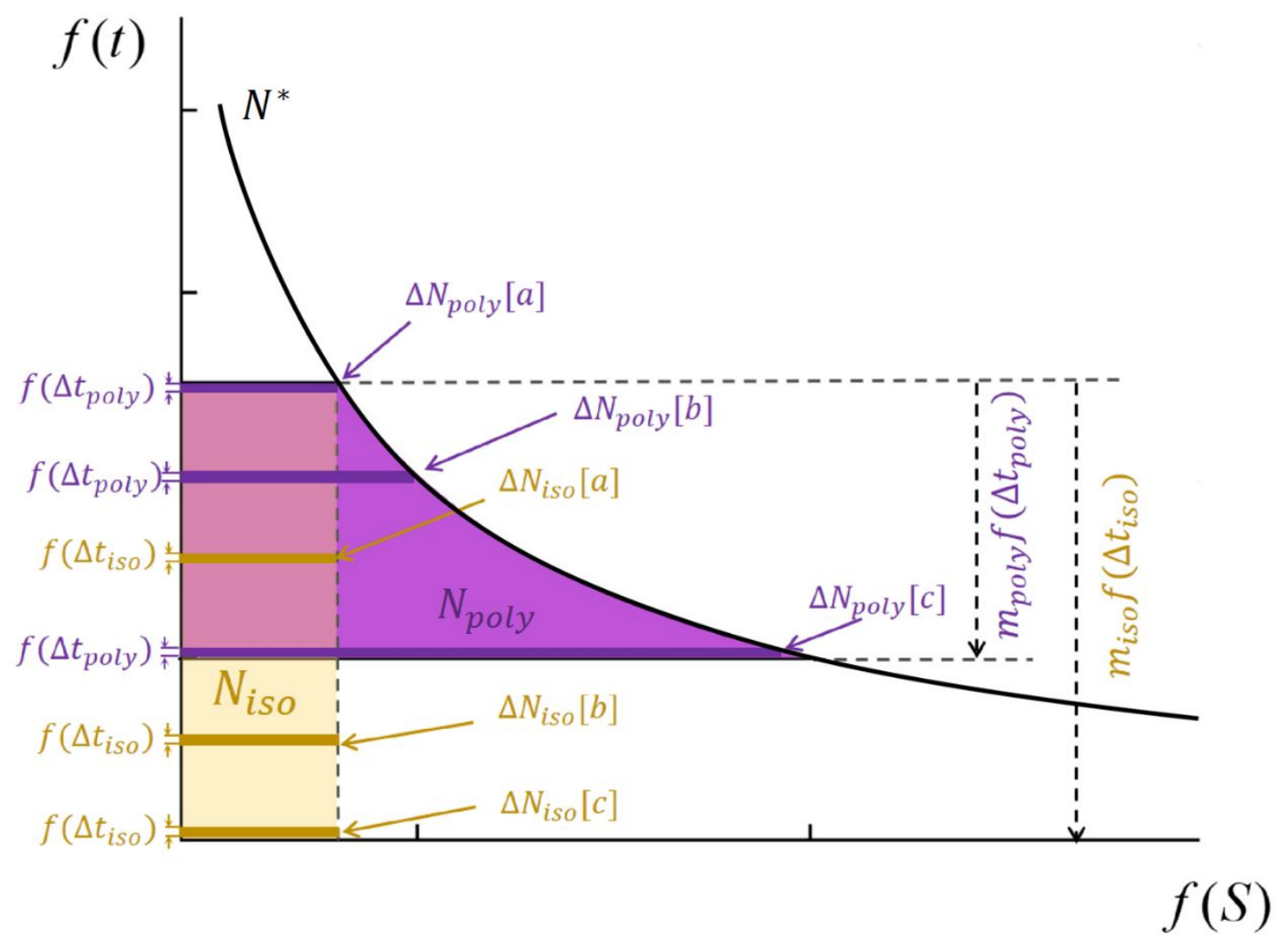

Fig.1 Interpretation of the isothermal experiment (brown) and the polythermal experiment (purple) by the classical nucleation theory with Eqs $(7,8$, and 9$)$.

The area of any system in isothermal experiment is always equal to $N^{*}$, i.e. $f\left(S_{i}\right.$ )$\times f\left(t_{i}\right)$ equal to a constant, shown in Figure 1, and therefore, the larger $f(S)$, i.e. supersaturation, is, the shorter $f(t)$, i.e. induction time, becomes. For example of isothermal process, $\Delta N_{\text {iso }}$ is nucleation potential in each unit $f(t)$ which is equal to 
the area of the small rectangle $\Delta f(\mathrm{t}) * f(S)$, and accumulation of all the $\Delta N_{\text {iso }}$ will reach $N^{*}$ at nucleation. For an isothermal experiment, the $\Delta N_{i s o}[\mathrm{a}, \mathrm{b}, \mathrm{c}]$ are constant during the whole nucleation process, due to the constant $f(S)$. While in a polythermal experiment, the $\Delta N_{\text {poly }}$ is increasing. For example, the supersaturation increase, i.e. $f(S)$ increases, the area in the order of $\Delta N_{\text {poly }}[\mathrm{c}]>[\mathrm{b}]>[\mathrm{a}]$, i.e. the accumulation of nucleation potential increases with increase in supersaturation, till reaching $N^{*}$ at nucleation. It is noticed that, when supersaturation in a polythermal process increases to the same supersaturation as in an isothermal process, the $\Delta N_{\text {poly }}$ equals to $\Delta N_{\text {iso }}$, i.e. same areas, at that moment. So if we know $N^{*}$ for a system, it is easy to calculate the same unit $\Delta N_{\text {iso }}$ at a constant supersaturation, as Eqn (8), and it is possible to calculate $\Delta N_{\text {poly }}$ based on each different $\Delta N_{\text {iso }}$ at different supersaturations, as Eqn (9).

$$
\begin{aligned}
& \Delta N_{\text {iso }}\left[S_{i}\right]=\frac{\Delta t}{t_{n}\left[S_{i}\right]} N^{*} \\
& \Delta N_{\text {poly }}\left[S_{i}\right]=\Delta N_{i s o}\left[S_{i}\right]=\frac{\Delta t}{t_{n}\left[S_{i}\right]} N^{*}
\end{aligned}
$$

$t_{n}\left[S_{i}\right]$ is a function of supersaturation, and can be calculated based on Eqn (7):

$$
t_{n}\left[S_{i}\right]=A V \exp \left(-\frac{N^{*}}{3 R^{3} T_{i}^{3}\left(\ln S_{i}\right)^{2}}\right) N^{*}
$$

Where the $T_{i}$ and $S_{i}$ are constant in an isotherm process, while the $S_{i}$ will change, dependent on cooling $T_{i}$ in a polythermal process.

As mentioned, for one system, despite of the process, all the nucleation occurs when the accumulation of $\Delta N$ (the accumulation of the area) equal to $N^{*}$. Therefore, the integration over time $t$ from the time constant supersaturation is generated $(t=0)$ to the time $t_{m}$ becomes:

$$
\int_{0}^{m \Delta t} \Delta N d t \approx \sum_{i=1}^{m} \Delta N=\mathrm{m} A \Delta t \exp \left[-\frac{N^{*}}{3 R^{3} T_{i}{ }^{3}\left(\ln S_{i}\right)^{2}}\right] N^{*}
$$


If $\Delta t$ is 1 second, then at $m$ second, when the accumulation equals to $N^{*}$, nucleation happens, or it is possible to direct integration of the equation (infinite small step) $)^{[19,20,32]}$.

The solubility of dicyandiamide in water ${ }^{[21]}$ at any temperature $T$ can be correlated by Eqn (11) with constant parameters $\mathrm{C}_{1}, \mathrm{C}_{2}, \mathrm{C}_{3}$, for estimation the $S_{i}$ based on the saturated temperature, $T_{0}$, and the solution temperature, $T_{i}$, and cooling rate $z_{n}$, and time period, $\mathrm{t}$, after solution becomes supersaturated,

$\ln x=C_{1}+\frac{C_{2}}{T}+C_{3} \ln T=C_{1}+\frac{C_{2}}{T_{i}}+C_{3} \ln T_{i}=C_{1}+\frac{C_{2}}{T_{0}-z_{n} t}+C_{3} \ln \left(T_{0}-z_{n} t\right)$

In some studies, the pre-exponential related to supersaturation ${ }^{[33]}$ (detailed in supporting information) was used,

$$
J=A_{S} \mathrm{~V} \cdot \ln S \exp \left(\frac{\Delta G^{*}}{R T}\right)
$$

so the Eqn (11) can be modified as

$$
\int_{0}^{m \Delta t} \Delta N d t \approx \sum_{i=1}^{m} \Delta N=\mathrm{m} A_{S} \mathrm{~V} \cdot \ln S \Delta t \exp \left[-\frac{N^{*}}{3 R^{3} T_{i}{ }^{3}\left(\ln S_{i}\right)^{2}}\right] N^{*}
$$

\section{Experimental section}

\section{Materials and Instrument}

The dicyandiamide (Analytical Grade, $\geqslant 99 \%$ mass fraction purity) was purchased from Beilite Chemical Co,Ltd), and used without further treatments. Deionized water (resistivity $=18.25 \mathrm{M} \Omega \cdot \mathrm{cm}$ ) was used.

\section{MSZW and Induction Time}

The dicyandiamide $(3.1536 \mathrm{~g})$ was dissolved in $100 \mathrm{ml}$ water to make a solution with a saturated temperature at $293.15 \mathrm{~K}$, and the concentration is $0.31 \mathrm{mg} / \mathrm{mg} \mathrm{H}_{2} \mathrm{O}$ based on the reported solubility ${ }^{[21]}$. The prepared solutions were filtered through PTFE 
membranes (pore size $=0.22 \mu \mathrm{m}$ ). $100 \mathrm{~mL}$ solution was put in a vessel with capacity of $150 \mathrm{~mL}$, stirring with a magnetic stirrer $(3 \mathrm{~mm} \times 20 \mathrm{~mm})$ at a rate of $1000 \mathrm{rpm}$. The vessel was sealed to avoid unnecessary evaporation.

The saturated solutions were maintained at a temperature of $298.15 \mathrm{~K}$, which was $5^{\circ} \mathrm{C}$ above the saturation temperature, for $30 \mathrm{~min}{ }^{[34]}$ to ensure the complete dissolution of the solute. In the isothermal experiments ${ }^{[35]}$, the solution was fast cooling down to $290.15 \mathrm{~K}, 289.65 \mathrm{~K}, 289.15 \mathrm{~K}, 288.65 \mathrm{~K}$, and $288.15 \mathrm{~K}$, respectively, with supersaturation ranging from 1.15 to 1.24 . Then the solutions were kept at a constant temperature until nucleation the tunability sharply increased, observed by a highprecised turbidity probe (Amphenol, USA). Programmed heating and cooling of the solution were controlled by EasyMax 102 (Mettler Toledo, Switzerland). After nucleation, the solutions were heated up to $298.15 \mathrm{~K}$ and maintain for 30 minutes to dissolve. In a polythermal experiment ${ }^{[35,36]}$, the solution at $298.15 \mathrm{~K}$ was cooled down with linear cooling rates $z_{c}$ at $6,12,18,24$, and $30 \mathrm{~K} / \mathrm{h}$ respectively. The induction time $t_{\text {ind }}$ in isothermal process and nucleation time in polythermal process were recorded as the time period from the time solution reached supersaturated to the time the nucleation occurred. A total of 177 nucleation experiments including and MSZW were determined, the experiments were repeated 15 - 22 times at each condition. 


\section{Results}

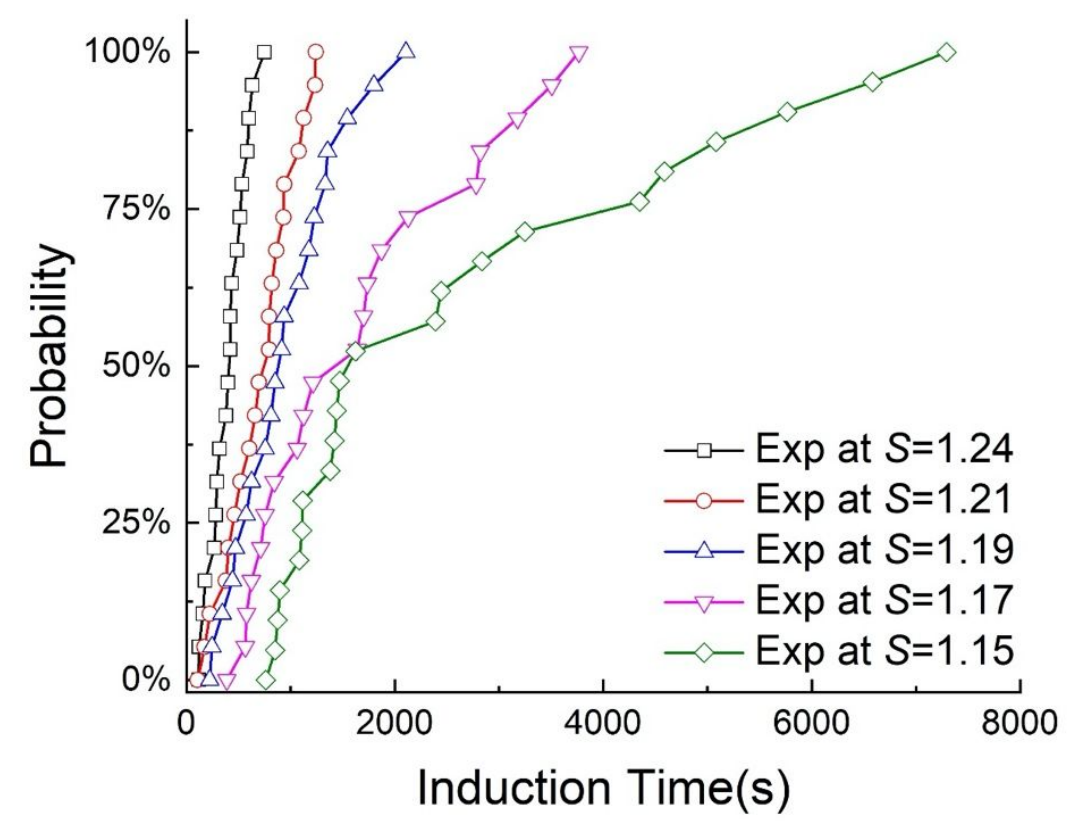

Fig. 2 Cumulative distributions of the induction times of dicyandiamide in water, at five different supersaturations, in the range of 1.15 to 1.24 .

The distributions of induction times and MSZWs in Fig. 2 and Fig. 3 all show the stochastic nature of nucleation. Fig. 2 shows the distributions of the induction time at the constant temperature $3 \mathrm{~K}$ to $5 \mathrm{~K}$ below the saturated temperature, with supersaturation of 1.15 to 1.24 . The induction times at supersaturation $S=1.19$ to $S=1.24$ were narrowly distributed and the longest induction time was about 2 times longer than the average induction time in each case. At the lower supersaturations $S=1.15$ and 1.17 , the longest induction time was about 4 times longer than the average induction time respectively. The standard deviations decreased from 1988 to $173 \mathrm{~s}$ with increase in supersaturation from 1.15 to 1.24 . The induction times at lower supersaturations tended to have wider distributions. 


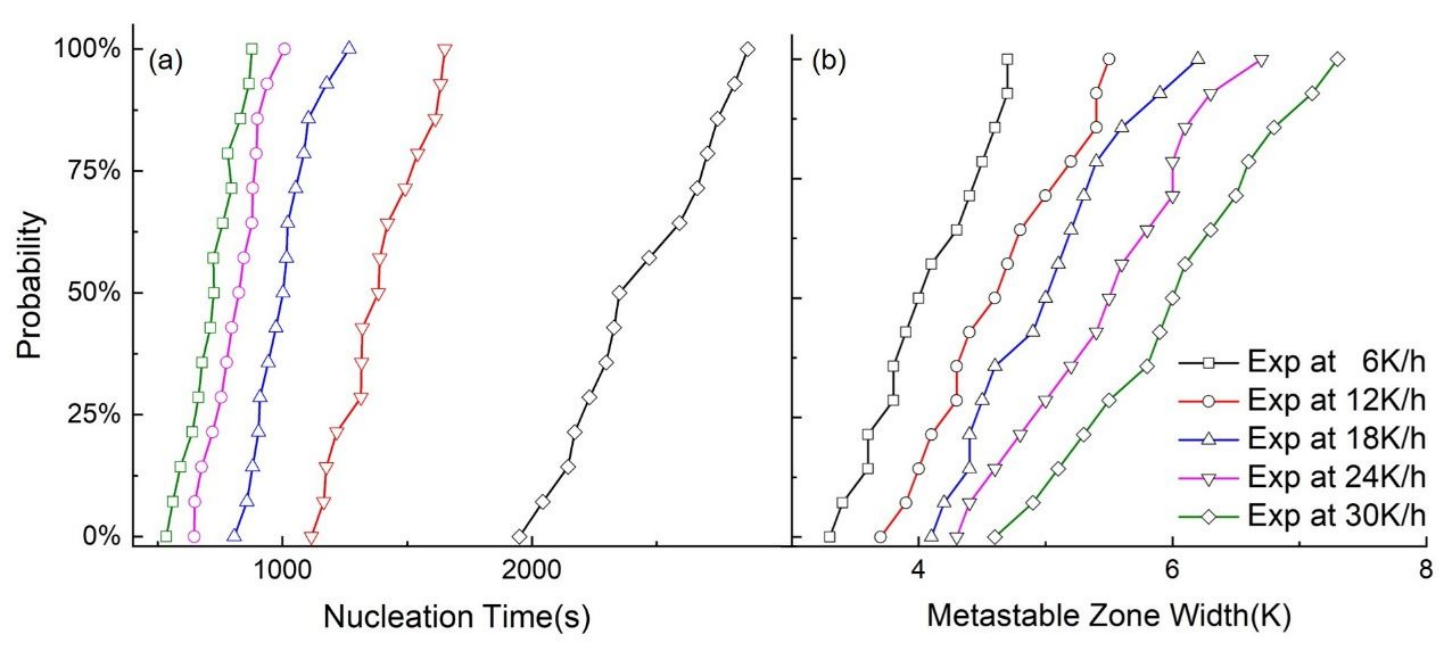

Fig. 3 Cumulative distributions nucleation times (a) and MSWZs(b) at five different cooling rates, at cooling rates from 6 to $30 \mathrm{~K} / \mathrm{h}$. The labels correspond to both figures.

Fig. 3(a) shows experimental results of 75 nucleation times with cooling rates from 6.0 to $30.0 \mathrm{~K} / \mathrm{h}$. Nucleation times in experiments with cooling rates of 18.0 to $30.0 \mathrm{~K} / \mathrm{h}$ were shorter than those with cooling rates of $12.0 \mathrm{~K} / \mathrm{h}$, and the nucleation times with cooling rates of $6.0 \mathrm{~K} / \mathrm{h}$ were about two times longer than those with cooling rates of 12.0 K/h. The standard deviations of nucleation times were $291,174,124,108,106$ $\mathrm{s}$ at cooling rates of $6,12,18,24$, and $30 \mathrm{~K} / \mathrm{h}$, respectively. Comparing with induction time deviations, the nucleation times in MSZW were more narrowly distributed. MSZWs were in the range of $3.3 \mathrm{~K}$ to $7.3 \mathrm{~K}$ for all the experiments. The average MSZW at each cooling rate was 4.1 to $6.0 \mathrm{~K}$ with standard deviations of 0.46 to $0.80 \mathrm{~K}$, increasing with decrease in cooling rates.

\section{Discussion}

\section{Nucleation parameters from induction time}

By fitting the results of experimental results, $\ln t_{\text {ind }}$ versus $T^{-3} \ln ^{-2} S$ (supporting information) with Eqn (4, 5 and 6), the critical nucleation energy was estimated to be 3 to $6 \mathrm{~kJ} / \mathrm{mol}$, the sizes of the critical nucleus were about $0.6-1 \mathrm{~nm}$, and the critical 
numbers of the nucleus were 10 to 40 at supersaturation of 1.24 to 1.15 , shown in Table 1. The interfacial energy, $\sigma$, of dicyandiamide in water was $2.8 \mathrm{~mJ} / \mathrm{m}^{3}$, and preexponential factor, $A V$, is $0.0058 s^{-1}$, which was in the same order as the values of some reported organic compounds ${ }^{[37-39]}$. Then, with interfacial energy, the $N^{*}$ of dicyandiamide in water was calculated to be $2.11 \mathrm{~kJ}^{3} / \mathrm{mol}^{3}$ by Eqn (7), and critical nucleation potential, $N$, was $1.28 \mathrm{~kJ} / \mathrm{mol}$.

Table 1 Induction time experimental results and nucleation parameters determined for dicyandiamide in water

\begin{tabular}{|c|c|c|c|c|c|c|c|}
\hline $\begin{array}{c}\mathrm{x}^{*} \\
\text { molar fraction }\end{array}$ & $\begin{array}{r}\mathrm{x}^{0} \\
\times 10^{3}\end{array}$ & $S$ & $\begin{array}{l}t_{\text {ind }} \\
{[/ s]}\end{array}$ & $\begin{array}{c}\sigma \\
{\left[\mathrm{mJ} / \mathrm{m}^{2}\right]}\end{array}$ & $\begin{array}{l}\mathrm{A} V \\
{[/ s]}\end{array}$ & $\begin{array}{c}G^{c} \\
{[\mathrm{~kJ} / \mathrm{mol}]}\end{array}$ & $\begin{array}{c}r^{c} \\
{[\mathrm{~nm}]}\end{array}$ \\
\hline 5.35 & 6.67 & 1.24 & $394(173)$ & 2.77 & 0.0058 & 2.52 & 0.60 \\
\hline 5.47 & & 1.21 & $703(333)$ & & & 3.11 & 0.66 \\
\hline 5.59 & & 1.19 & $940(501)$ & & & 3.92 & 0.75 \\
\hline 5.71 & & 1.17 & $1650(1031)$ & & & 5.11 & 0.86 \\
\hline 5.84 & & 1.15 & 2664(1988) & & & 6.93 & 0.99 \\
\hline
\end{tabular}

$\mathrm{t}_{\text {ind }}$ : average induction time with standard deviation in brackets. $\mathrm{x}^{*}$ : molar solubility of the solution at each constant temperature. x: concentration of the solution. $\sigma$ : interfacial energy of solid and liquid. $A V$ : pre-exponential factor in the solution with volume $\mathrm{V} . \mathrm{r}_{\mathrm{c}}$ : critical radius of a nucleus. $\mathrm{n}_{\mathrm{c}}$ : critical number of molecules in a nucleus. $\mathrm{x}^{0}, \sigma$ and $A V$ are constant for all five conditions.

\section{Nucleation potential}

In isothermal process, the accumulation of $\Delta N$ increased linearly as shown in Fig. 4a, at nucleation $\sum \Delta N$ equaled to $N^{*}$, i.e. the areas $\left(\sum \Delta N \times \Delta t\right)$ of the rectangle in Fig. 4b. Fig 4 shows that the accumulation rates keep constant with constant supersaturations, but $N^{*}$ was constant for all the condtions, for example the area of the rectangle for the condition $S=1.15$ in Fig $4 b$. 


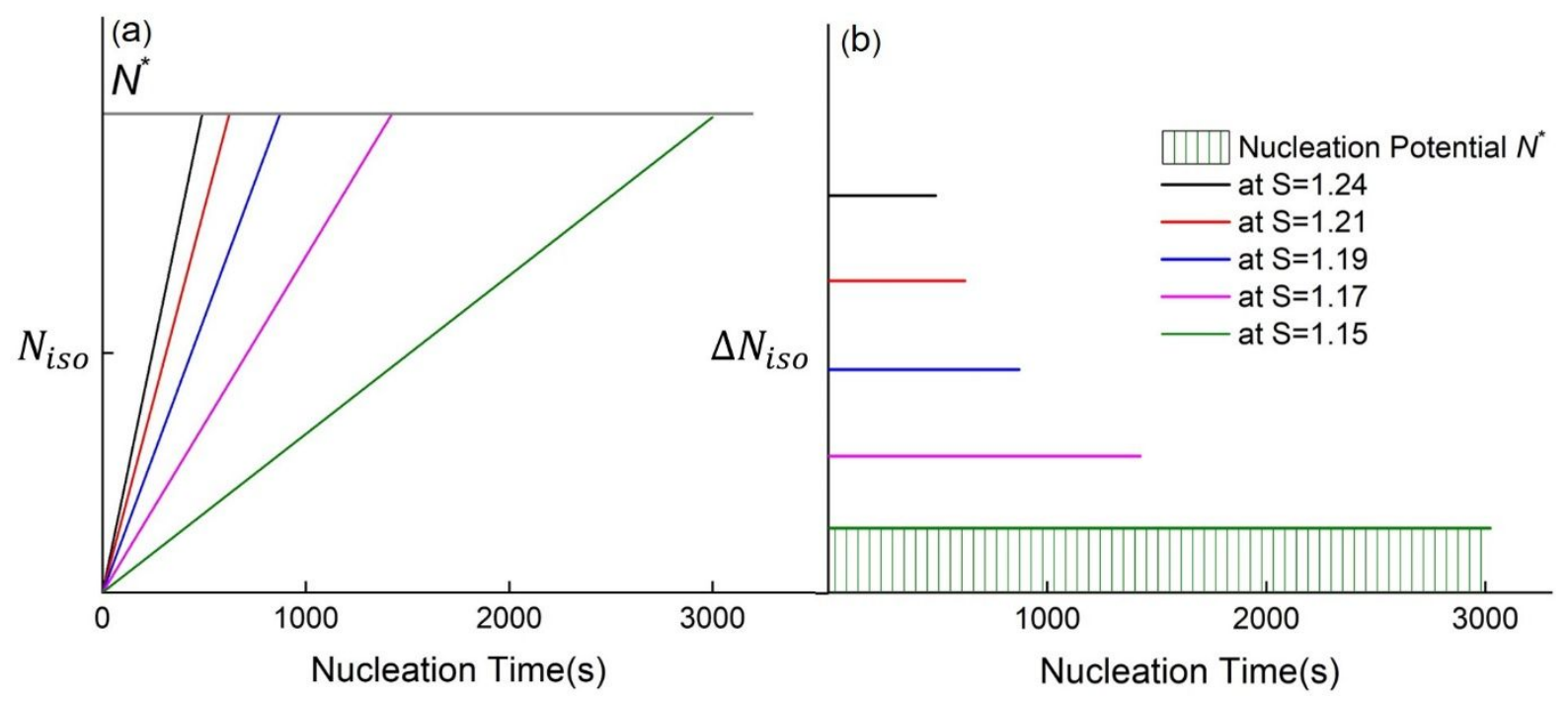

Fig. 4 Accumulation of the nucleation potential, $\Sigma \Delta N$, and the nucleation potential $\Delta \boldsymbol{N}$ over time with Eqn. (10) in isothermal process. The labels correspond to both figures.

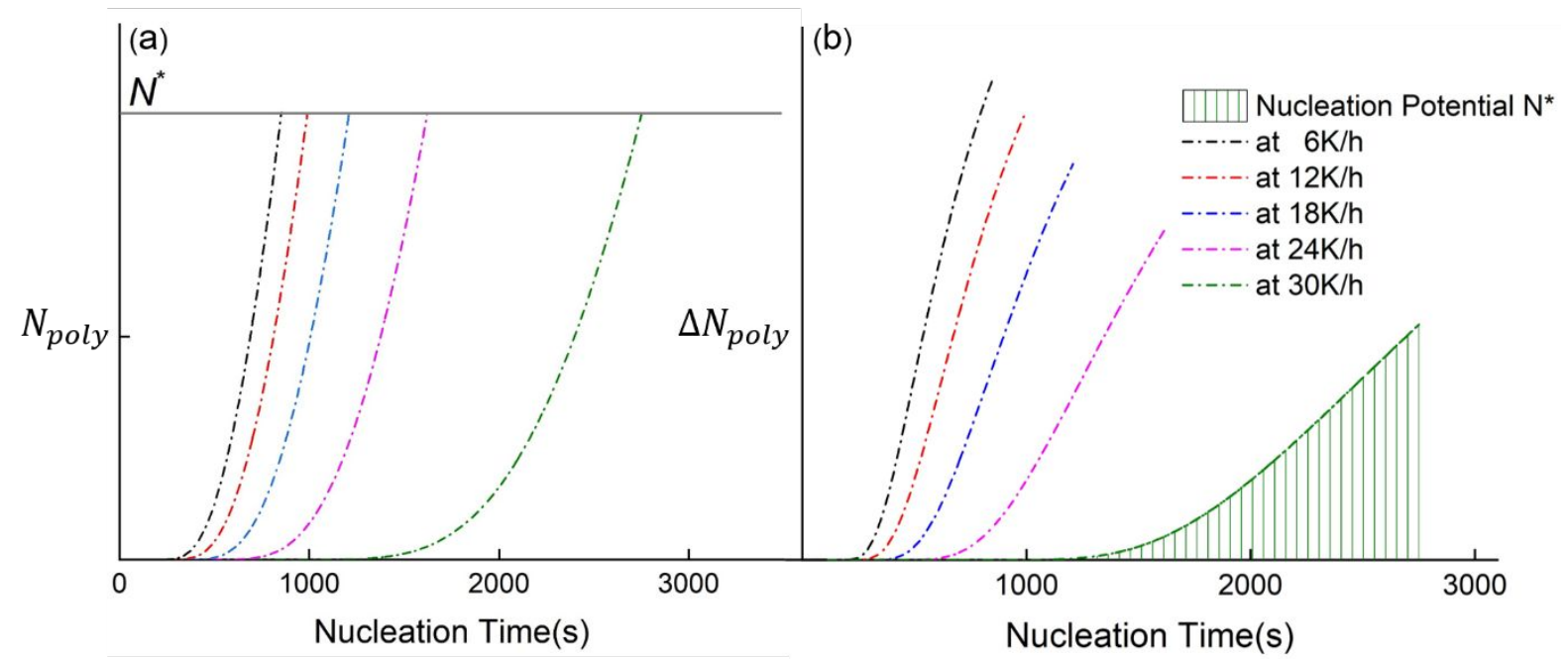

Fig. 5 Accumulation of the nucleation potential, $\Sigma \Delta N$, and the nucleation potential $\Delta N$ over time with Eqn. (10) in polythermal process. The labels correspond to both figures.

In polythermal processes, the solution temperature continuously decreased and the $S$ increased before nucleation, and, therefore, the accumulation rate of the nucleation potential increased with time as shown in Fig. 5(a). The $\Sigma \Delta N$ equaled to $\mathrm{N}^{*}$, for example the area $\left(\sum \Delta N \times \Delta t\right)$ for the condition $30 \mathrm{~K} / \mathrm{h}$ in Fig. $5 \mathrm{~b}$. Fig 5 shows 
that the accumulation rates increased with increase in supersaturation, but $\mathrm{N}^{*}$ was constant for all the conditions, i.e. the areas in Fig 5b. It is noticed that, at the early stages of the cooling process, there is only negligible nucleation potential accumulated, due to very low supersaturation in the solution. It would cost $80 \%$ of the nucleation time for $\sum \Delta N$ to reach half value of $N^{*}$.

For the dicyandiamide - water system, During an isothermal process, the nucleation potential $N_{\text {iso }}$ correspond to nucleation time. The nucleation growth $\Delta N_{i s o}$ stay the same, and with larger supersaturation, $\Delta N$ became larger, and a narrower distributions of induction time was observed. In a polythermal process, the potential accumulation process was highly accelerated in the final stage when the accumulated $N$ closely approached to $N^{*}$, i.e. the system was more closed to nucleation, the larger $\Delta N_{\text {poly }}$ became. It was also observed that when the induction time in a isothermal process and nucleation time in a polythermal process were in the similar range, the distribution of nucleation time in a polythermal process was narrower than induction time distribution in a isothermal process. It can be inferred that the fast accumulation rate of nucleation potential tended to narrow the distribution of the nucleation times and induction times.

\section{Extrapolated MSZW from induction time}

With the accumulation of the nucleation potential, nucleation would occur at $\sum_{i=1}^{m} \Delta N \geqslant 2.11 \mathrm{~kJ}^{3} / \mathrm{mol}^{3}$, both in the isothermal and polythermal process for the system of the dicyandiamide in water. Therefore, a minimum value $\mathrm{m} s$ for polythermal process can be estimated to be the nucleation time (if $\Delta t=1 \mathrm{~s}$ ), and MSZW can be calculated based on the cooling rates. The MSZWs was estimated to be 4.05 to 5.99 $\mathrm{K}$ at the cooling rates of 6 to $30 \mathrm{~K} / \mathrm{h}$, with the extrapolated $\mathrm{m}$ values from 2752 to 853 
s, shown in Figure 6.

Table 2 Results of the experimental and extrapolated MSZWs of dicyandiamide in water with Eqn (11) at cooling rates of $6,12,18,24,30 \mathrm{~K} / \mathrm{h}$.

\begin{tabular}{|c|c|c|c|c|c|c|}
\hline $\begin{array}{c}z_{c} \\
{[\mathrm{~K} / \mathrm{h}]}\end{array}$ & $\begin{array}{l}T_{0} \\
{[\mathrm{~K}]}\end{array}$ & $\begin{array}{c}\text { MSZW } \\
{[\mathrm{K}]}\end{array}$ & $\begin{array}{c}t_{\mathrm{MSZW}} \\
{[\mathrm{s}]}\end{array}$ & $\begin{array}{c}N \\
{[\mathrm{~kJ} / \mathrm{mol}]}\end{array}$ & $\begin{array}{l}A V \\
{[/ \mathrm{s}]}\end{array}$ & $\begin{array}{c}M^{M S Z W} W_{\text {ind }} \\
{[K]}\end{array}$ \\
\hline 6 & 298.15 & $4.05(0.46)$ & 2351 & 1.28 & 0.0058 & 4.58 \\
\hline 12 & & $4.62(0.58)$ & 1385 & & & 5.41 \\
\hline 18 & & $5.01(0.62)$ & 1002 & & & 6.04 \\
\hline 24 & & $5.45(0.72)$ & 825 & & & 6.60 \\
\hline 30 & & $5.99(0.80)$ & 725 & & & 7.11 \\
\hline
\end{tabular}

$\mathrm{MSZW}_{\text {ind }}$ : MSZW estimated from experimental induction times.

Table 2 shows that, at each cooling rate, the extrapolated MSZW was in the range of the experimental values. All the extrapolated values are higher than the respective experimental values, and with increase in the cooling rates. At $6.0 \mathrm{~K} / \mathrm{h}$, the extrapolated value from induction time were only $0.5 \mathrm{~K}$ higher than the average value of the experimental MSZWs, and the differences between extrapolated values and the average experimental values increased from 0.5 to $1.1 \mathrm{~K}$.

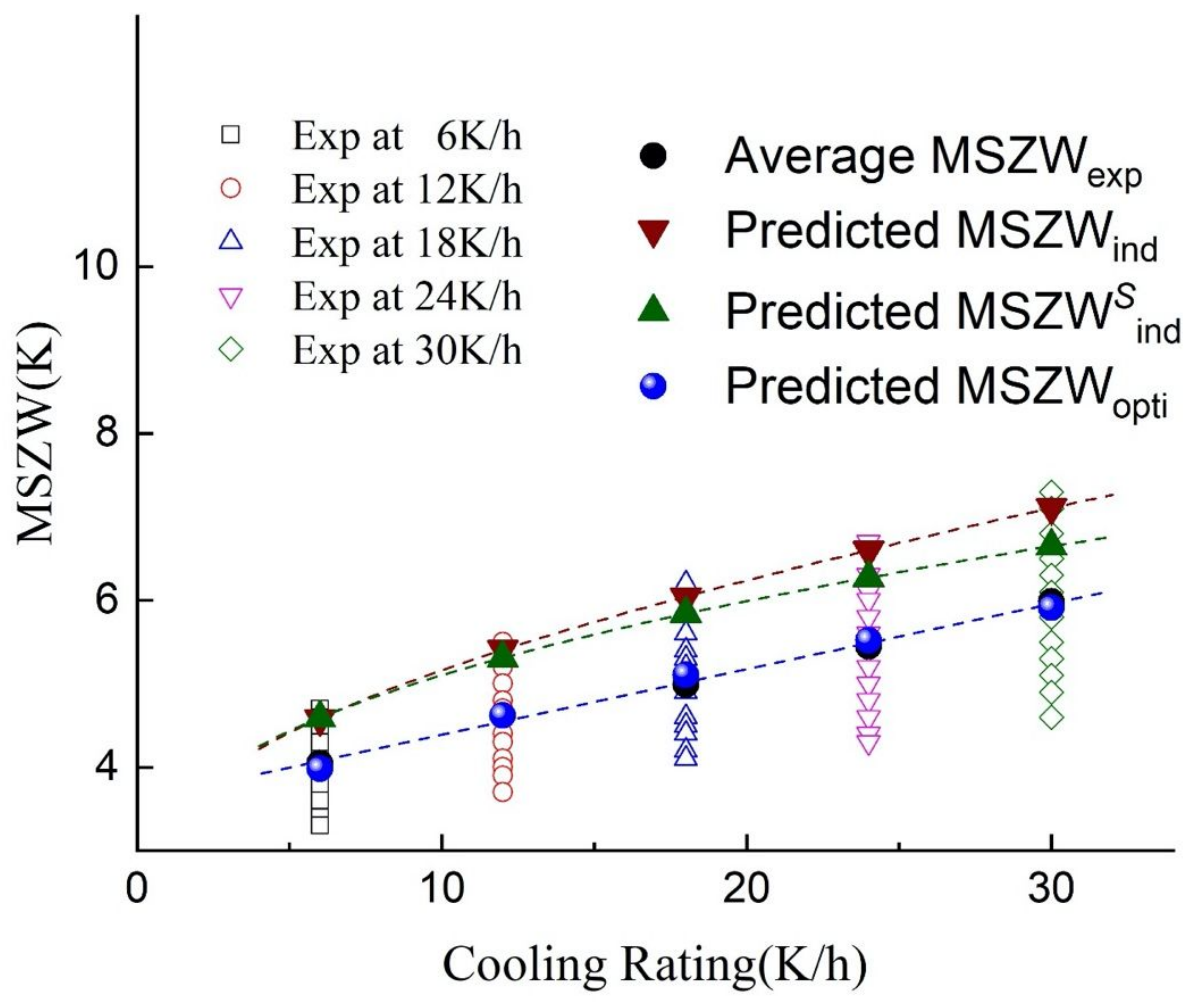

Fig. 6 Experimental results of dicyandiamide $M S Z W$ (open dot) in water with average values (black round solid dots), $M S Z W_{\text {ind }}$ extrapolated by using Eqn. (11) 
from induction time experiments (red inverted triangle) at cooling rates of $6,12,18,24,30 \mathrm{~K} / \mathrm{h}$ (from left to right), respectively. $M S Z W^{S}{ }_{\text {ind }}$ extrapolated from induction time experiments by using Eqn. (14) with supersaturation-dependence preexponential factor (olive positive triangle). $M S Z W_{\text {opti }}$ optimized from the target function with changeable nucleation parameters using Eqn. (15) (bull ball dots). Dashed lines are guiding lines of respective data.

\section{Extrapolated induction time from MSZW}

The nucleation parameters $A V$ and $N^{*}$ are a bridge to estimate induction times from MSZWs, despite that $A V$ and $N^{*}$ were unable to directly determined from experimental MSZWs. To estimate $A V$ and $N^{*}$, an global optimization method was applied, to find the best fitting between the average experimental MSZWs with estimated MSZWs (from a combination of given $A V$ and $N^{*}$ ) at each cooling rate. The optimization function, Eqn. (15), which is the total least square of deviation between experimental MSZWs and estimated MSZWs, was used to find the most closed fitting.

$$
F_{\text {opt } \mathrm{i}}=\sum_{i=z_{c}}\left(M S Z W_{\text {exp }}-M S Z W_{\text {est }}\right)^{2} \mid\left(N^{*}, A V\right)
$$

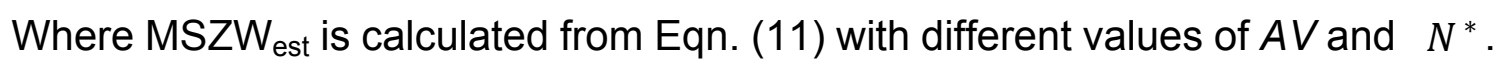
Optimization Toolbox in Matlab 2019a was used to find a minimum of unconstrained bivariate function Eqn. (15). The combination values of $N^{*}$ and $A V$, leading to the minimum $F_{\text {opti, }}$ were used to estimate induction times.

Table 3 Estimated nucleation parameters from IT and MSZW.

\begin{tabular}{cccc}
\hline Estimation method & $N^{*}$ & $A V$ & $\sigma$ \\
& {$\left[\mathrm{kJ}^{3} / \mathrm{mol}^{3}\right]$} & {$[/ s]$} & {$\left[\mathrm{mJ} / \mathrm{m}^{2}\right]$} \\
\hline from induction time $^{\mathrm{a}}$ & 2.11 & 0.0058 & 2.77 \\
\hline
\end{tabular}


a the nucleation parameters were fitted by Eqn. (9) through experimental induction times. ${ }^{b}$ the nucleation parameters were solved through the optimization method from Eqn. (15) through experimental metastable zone width

$N^{*}$ and $A V$ from the best fitting MSZW values, $M S Z W_{\text {opti }}$ (shown in Fig.7), with $F_{\text {opt }}$ of $0.0289 \mathrm{~K}^{2}$, were estimated to be $1.87 \mathrm{~kJ}^{3} / \mathrm{mol}^{3}$ and $0.0091 / \mathrm{s}$, respectively. The interfacial energy estimated from MSZW was $2.7 \mathrm{~mJ} / \mathrm{m}^{2}$, which was very close to the value determined from induction times $2.8 \mathrm{~mJ} / \mathrm{m}^{2}$. As interfacial energy is a key parameter to determine the difficulties of the formation of the nucleus, and the consistent results from induction time and MSZW helps to understand the nucleation phenomena. The pre-exponential factors were $0.0058 \mathrm{ls}$ from induction time and 0.0091 /s from MSZW shown in Table 3. Based on AV and interfacial energy $\sigma$, the induction times can be estimated, which compared with experimental values in Fig. 7. The estimated induction times were all in the range of the experimental values at each supersaturation, however, the estimated values were all below the average induction times. At lower supersaturation, the difference between estimated values and experimental values decreased to $1593 \mathrm{~s}$. 


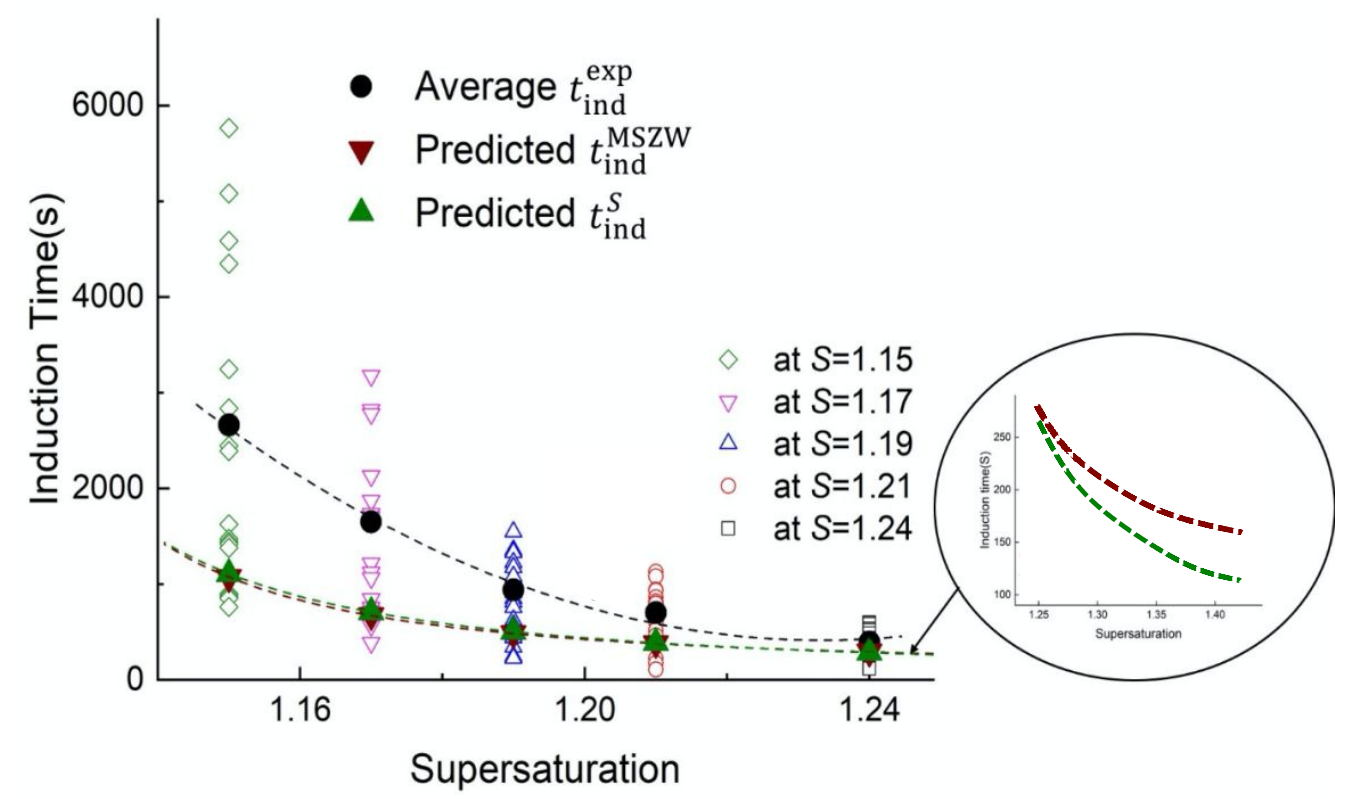

Fig. 7 Experimental, $\boldsymbol{t}_{\boldsymbol{i n d}}^{\text {exp }}$, and predicted results of induction time in dicyandiamidewater system with constant supersaturation at 1.15 to 1.24 in the isothermal process. $\boldsymbol{t}_{\text {ind }}^{M S Z W}$ extrapolated by using Eqn. (11) with constant pre-exponential factor from induction time experiments (red inverted triangle). $\boldsymbol{t}_{\boldsymbol{i n d}}^{S}$ extrapolated from induction time experiments through supersaturation-dependence pre-exponential factor by using Eqn. (14) (olive positive triangle).

\section{Modified pre-exponential factor}

The pre-exponential factor was assumed to be constant ${ }^{[1]}$ in Eqn (7) and (10), here the pre-exponential factor was explored as $A_{S} \ln S$, which was modified to be dependent on the supersaturation as literatures ${ }^{[33]}$, and Eqn (14) were used to investigate the correlation between induction time and MSWZs. The parameters $A_{s} V$ was estimated to be $0.027 / \mathrm{s}$ and $N_{s}^{*}$ was $1.82 \mathrm{~kJ}^{3} / \mathrm{mol}^{3}$ With similar method described above, the Eqn (14) with supersaturation-dependent pre-exponential factor led to extrapolated MSZWs, MSZW modified pre-exponential factor were all in the range of the experimental values, and got more closer $20 \%$ to the experimental values compared with the predicted MSWZ 
with constant pre-exponential factor.

The optimization function, Eqn. (15), was used to establish the induction time from MSZWs. The optimized nucleation parameters $A_{S} V$ and $N_{S}^{*}$ were $1.34 \mathrm{~kJ}^{3} \mathrm{~mol}^{-3}$ and $0.033 / s$, respectively. It is noticed that at lower supersaturation, the predicted MSZWs by Eqn (11) and (14) are closer, and at higher supersaturation the difference became larger, due to the influence of the shorter estimated induction time values by Eqn (14) in higher supersaturation as Fig. 7 shown. The pre-exponential factor, dependent on the supersaturation, improved the nucleation model in high supersatuation, but futher investigations are still needed for accurater prediction of the nucleation parameter from both induction times and MSZWs and wider applications of the nucleation potential models on more complicated cooing profiles, leading to better understanding the nucleation behaviours in the isothermal and polythermal processes.

\section{Conclusion}

In total, 177 nucleation experiments, including MSZWs, with average values of $3.3-7.3 \mathrm{~K}$ at cooling rate from $6-30 \mathrm{~K} / \mathrm{h}$, and induction times, with average values of 725 - 2351s, at supersaturation from 1.15 to 1.24 , were performed in the system of dicyandiamide aqueous solutions. The nucleation potential model with constant preexponential factor was used to correlate the MSZWs and induction times, and accumulated nucldeation potential increased linearly in isothermal process and grew faster in polythermal process till nucleation to reach critical nucleation potential. With the nucleation potential model, the interfacial energy, $2.66 \mathrm{~mJ} / \mathrm{m}^{2}$, was determined from MSWZs, which were consistent with that determined from induction times by classical nucleation theory. The estimated MSWZs from induction times and estimated induction times from MSZWs were all in the range of the experimental results of 
MSWZs and induction times, respectively. The nucleation potential model with a variable pre-exponential factor, dependent on the supersaturation, was explored, generating closer fitting between estimated MSZWs and induction times with the experimental values. Further research on the dependency of the pre-exponential factor and interfacial energy on the supersaturation, temperature or other factors, are still needed for better synchronize the understanding of nucleation behaviours in isothermal and polythermal processes.

\section{Acknowledgements}

Authors thank for the financial support by the National Natural Science Foundation of China (NSFC, No. 22078093).

\section{Nomenclature}

$\begin{array}{cl}A V, A_{s} V & \text { Pre-exponential [/s] } \\ C_{1} C_{2}, C_{3} & \text { Constants in the solubility Equation } \\ f(S) & \text { Function of supersaturation }\left[\mathrm{J}^{3} / \mathrm{mol}^{3}\right] \\ f(t) & \text { Function of nucleation time } \\ \mathrm{m} & \text { Integer number in the accumulation Nucleation } \\ \mathrm{i} & \text { Integer number variable from } 1 \text { to } \mathrm{n} \\ n_{c} & \text { Number of molecules in critical nucleus } \\ N & \text { Critical nucleation potential }[\mathrm{J} / \mathrm{mol}] \\ N^{*} & \text { Nucleation potential }\left[\mathrm{J}^{3} / \mathrm{mol}^{3}\right] \\ J & \text { Nucleation rate }[/ \mathrm{s}] \\ r_{c} & \text { Radius of critical nucleus }[\mathrm{m}] \\ \mathrm{R} & \text { Ideal gas constant, } 8.314[\mathrm{~J} / \mathrm{mol} / \mathrm{K}] \\ \mathrm{S} & \text { Supersaturation } \\ \mathrm{t}_{\text {ind }} & \text { Induction time }[\mathrm{s}] \\ t, t_{i} & \text { Time during nucleation }[\mathrm{s}] \\ T, T_{i} & \text { Temperature during nucleation }[\mathrm{K}] \\ v_{m} & \text { Molar volume of the solute }\left[\mathrm{m}^{3} / \mathrm{mol}\right] \\ x_{0} & \text { Solute molar fraction solubility } \\ x^{*} & \text { Equilibrium solute molar fraction } \\ z_{c} & \text { Coling rate }[\mathrm{K} / \mathrm{s}] \\ \sigma & \left.\text { Interfacial energy }[\mathrm{m}] / \mathrm{m}^{2}\right] \\ \Delta G & \text { Free energy }[\mathrm{J} / \mathrm{mol}]\end{array}$




\section{$\Delta N_{i}, \Delta N_{i s o}, \Delta N_{\text {poly }}$ Nucleation potential accumulated during $\Delta \mathrm{t}\left[\mathrm{J}^{3} / \mathrm{mol}^{3}\right]$}

\section{Reference}

[1] Kashchiev D. Nucleation: basic theory with applications. $1^{a}$ edição[M]. Butterworth Heinemann. Grã-Britânia, 2000.

[2] Omar H M, Rohani S. Crystal population balance formulation and solution methods: a review[J]. Crystal Growth \& Design, 2017, 17: 4028-4041.

[3] Wang T, Lu H, Wang J, et al. Recent progress of continuous crystallization[J]. Journal of Industrial Engineering Chemistry, 2017, 54: 14-29. 2002.

[4] Myerson A. Handbook of industrial crystallization[M]. Butterworth-Heinemann,

[5] Kadam S S, Kulkarni S A, Ribera R C, et al. A new view on the metastable zone width during cooling crystallization[J]. Chemical engineering science, 2012, 72: 10-19.

[6] Volmer M, Weber A. Germ-formation in oversaturated figures[J]. Z. phys. chem, 1926, 119: 277-301.

[7] Becker R, Döring W. The kinetic treatment of nuclear formation in supersaturated vapors[J]. Ann. Phys, 1935, 24: 752.

[8] Frenkel J. A general theory of heterophase fluctuations and pretransition phenomena[J]. The Journal of Chemical Physics, 1939, 7: 538-547.

[9] Karthika S, Radhakrishnan T, Kalaichelvi P. A review of classical and nonclassical nucleation theories[J]. Crystal Growth \& Design, 2016, 16: 6663-6681.

[10] Agarwal V, Peters B. Solute precipitate nucleation: A review of theory and simulation advances[J]. Advances in Chemical Physics: Volume 155, 2014: 97-160.

[11] Erdemir D, Lee A Y, Myerson A S. Nucleation of crystals from solution: classical and two-step models[J]. Accounts of chemical research, 2009, 42: 621-629.

[12] Pan W, Kolomeisky A B, Vekilov P G. Nucleation of ordered solid phases of proteins via a disordered high-density state: Phenomenological approach[J]. The Journal of chemical physics, 2005, 122: 174905.

[13] Wang Q, Gao P, Wang X, et al. The early diagnosis and monitoring of squamous cell carcinoma via saliva metabolomics[J]. Scientific reports, 2014, 4: 1-9.

[14] Su N, Wang Y, Xiao Y, et al. Mechanism of influence of organic impurity on crystallization of sodium sulfate[J]. Industrial Engineering Chemistry Research, 2018, 57: $1705-1713$.

[15] Li L, Zhao S, Xin Z, et al. Nucleation kinetics of Clopidogrel hydrogen sulfate Polymorphs in Reactive crystallization: Induction period and Interfacial tension measurements[J]. Journal of Crystal Growth, 2020: 125610.

[16] Zhang X, Yang Z, Chai J, et al. Nucleation kinetics of lovastatin in different solvents from metastable zone widths[J]. Chemical Engineering Science, 2015, 133: 62-69.

[17] Bhamidi V, Kenis P J, Zukoski C F. Probability of nucleation in a metastable zone: induction supersaturation and implications[J]. Crystal Growth \& Design, 2017, 17: 1132-1145.

[18] Kubota N. A unified interpretation of metastable zone widths and induction times measured for seeded solutions[J]. Journal of crystal growth, 2010, 312: 548-554.

[19] Shiau L-D. Comment on "Relation between metastable zone width and induction time of butyl paraben in ethanol" by H. Yang, CrystEngComm, 2015, 17, 577[J]. CrystEngComm, 2015, 17: 4402-4404.

[20] Shiau L-D. Comparison of the interfacial energy and pre-exponential factor 
calculated from the induction time and metastable zone width data based on classical nucleation theory[J]. Journal of Crystal Growth, 2016, 450: 50-55.

[21] Zhang X, Qian G, Yang X, et al. Solid-liquid equilibrium of dicyandiamide in different solvents[J]. Fluid Phase Equilibria, 2014, 363: 228-232.

[22] Yang H, Florence A J. Relating induction time and metastable zone width[J]. CrystEngComm, 2017, 19: 3966-3978.

[23] Hughes E. The crystal structure of dicyandiamide[J]. Journal of the American Chemical Society, 1940, 62: 1258-1267.

[24] Hagnauer G L, Dunn D A. Dicyandiamide analysis and solubility in epoxy resins[J]. Journal of Applied Polymer Science, 1981, 26: 1837-1846.

[25] Carneiro J, Cardenas L, Hatch D, et al. Effect of the nitrification inhibitor dicyandiamide on microbial communities and $\mathrm{N}_{2} \mathrm{O}$ from an arable soil fertilized with ammonium sulphate[J]. Environmental Chemistry Letters, 2010, 8: 237-246.

[26] Zhao X, Pachfule P, Li S, et al. Bifunctional Electrocatalysts for Overall Water Splitting from an Iron/Nickel - Based Bimetallic Metal - Organic Framework/Dicyandiamide Composite[J]. Angewandte Chemie, 2018, 130: 9059-9064.

[27] Yang L, Liu X, Liu Z, et al. Enhanced photocatalytic activity of g-C3N4 2D nanosheets through thermal exfoliation using dicyandiamide as precursor[J]. Ceramics International, 2018, 44: 20613-20619.

[28] Xiao Y, Wang J, Huang X, et al. Determination methods for crystal nucleation kinetics in solutions[J]. Crystal Growth \& Design, 2018, 18: 540-551.

[29] Wantha L. Determination of Nucleation and Growth Mechanisms of the B Polymorph of L - Histidine by Induction Time Measurement[J]. Chemical Engineering \& Technology, 2016, 39: 1289-1294.

[30] Kodera T, Kobari M, Hirasawa I. Experimental Estimation of Primary and Secondary Nucleation Kinetics of Antisolvent Crystallization As Measured by Induction Time[J]. Organic Process Research \& Development, 2019, 23: 2724-2732.

[31] Xu S, Wang J, Zhang K, et al. Nucleation behavior of eszopiclone-butyl acetate solutions from metastable zone widths[J]. Chemical Engineering Science, 2016, 155: 248-257.

[32] Shiau L-D, Lu T-S. A model for determination of the interfacial energy from the measured metastable zone width by the polythermal method[J]. Journal of crystal growth, 2014, 402: 267-272.

[33] Kashchiev D, Van Rosmalen G. Nucleation in solutions revisited[J]. Crystal Research and Technology: Journal of Experimental and Industrial Crystallography, 2003, 38: 555-574.

[34] You S, Zhang Y, Zhang Y. Nucleation of ammonium aluminum sulfate dodecahydrate from unseeded aqueous solution[J]. Journal of Crystal Growth, 2015, 411: 2429.

[35] Garside J, Mersmann A, Nývlt J. Measurement of crystal growth and nucleation rates[M]. IChemE, 2002.

[36] Mullin J. Industrial techniques and equipment[J]. Crystallization (Fourth Edition), Butterworth-Heinemann, Oxford, 2001: 315-402.

[37] Omar W, Mohnicke M, Ulrich J. Determination of the solid liquid interfacial energy and thereby the critical nucleus size of paracetamol in different solvents[J]. Crystal Research and Technology: Journal of Experimental and Industrial Crystallography, 2006, 41: 337-343.

[38] Hou J, Wu S, Li R, et al. The induction time, interfacial energy and growth mechanism of maltitol in batch cooling crystallization[J]. Crystal Research and Technology, 2012, 47: 888-895.

[39] Lenka M, Sarkar D. Determination of metastable zone width, induction period and primary nucleation kinetics for cooling crystallization of L-asparaginenohydrate[J]. Journal of 
crystal growth, 2014, 408: 85-90. 


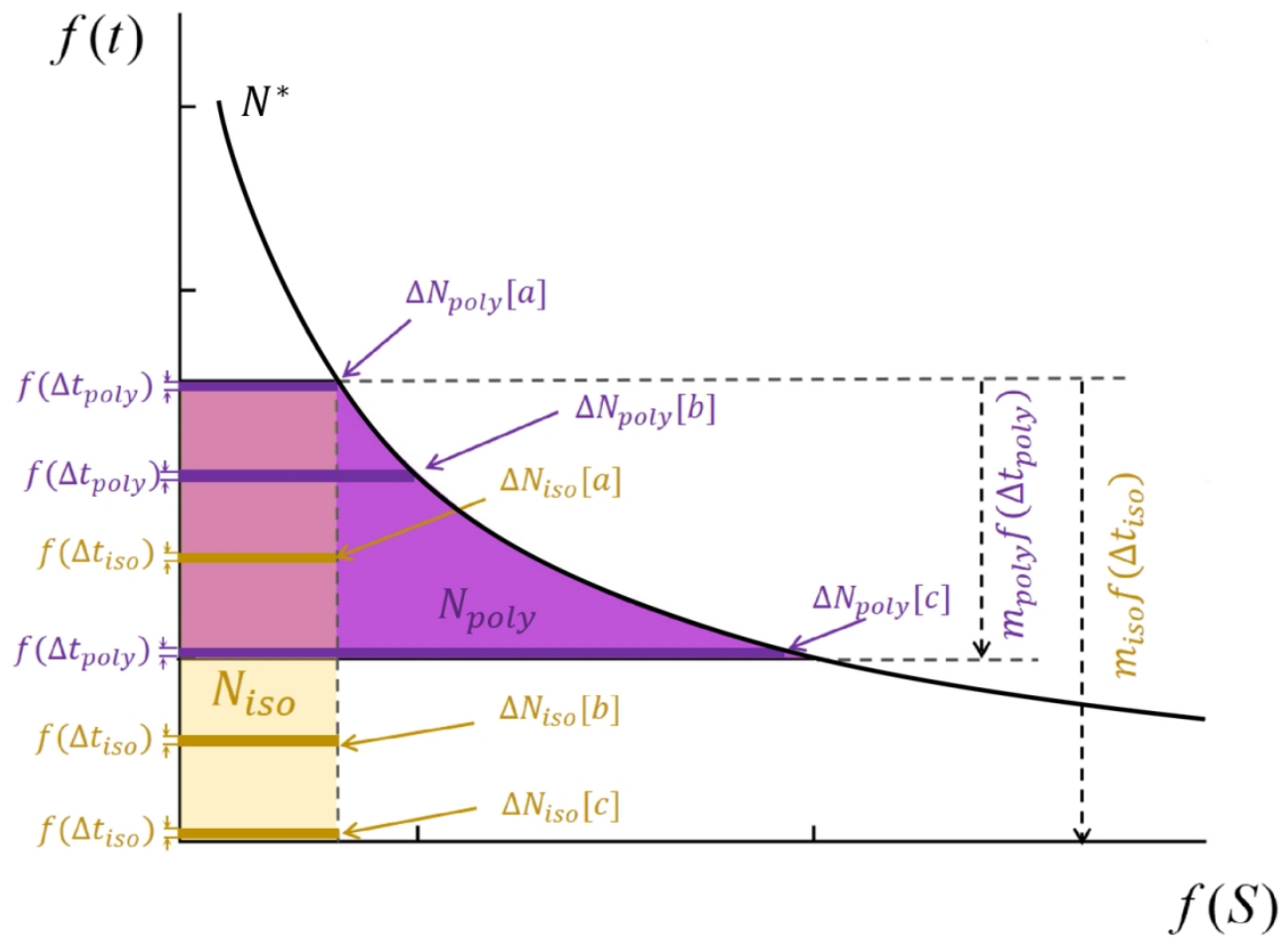

$249 \times 182 \mathrm{~mm}(150 \times 150 \mathrm{DPI})$ 


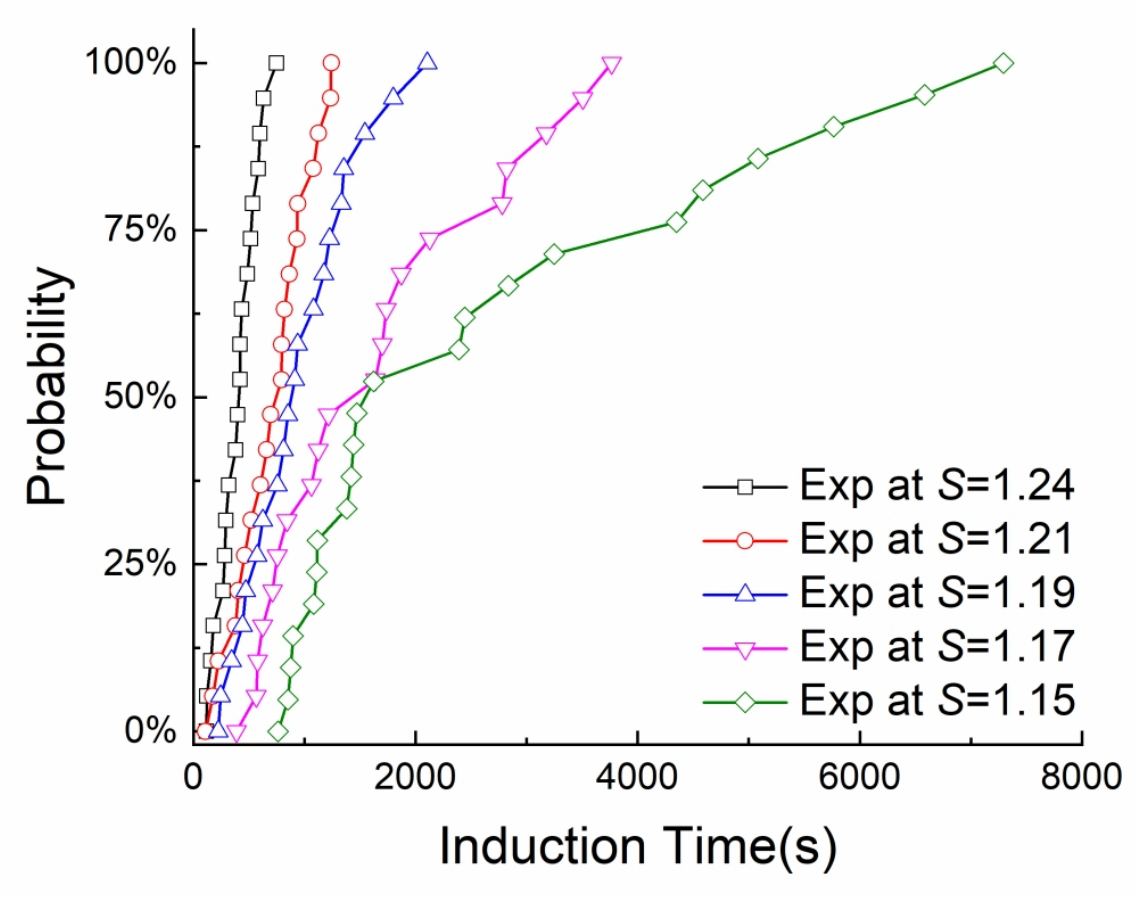

$272 \times 208 \mathrm{~mm}(300 \times 300$ DPI $)$ 


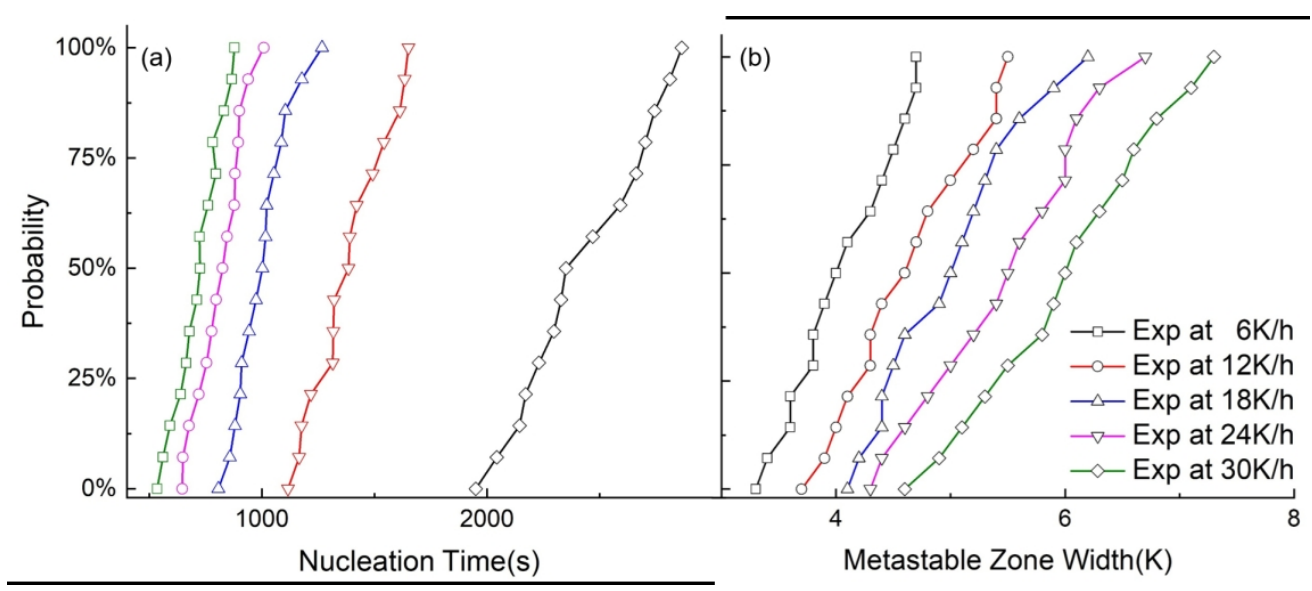

$323 \times 140 \mathrm{~mm}(150 \times 150 \mathrm{DPI})$ 


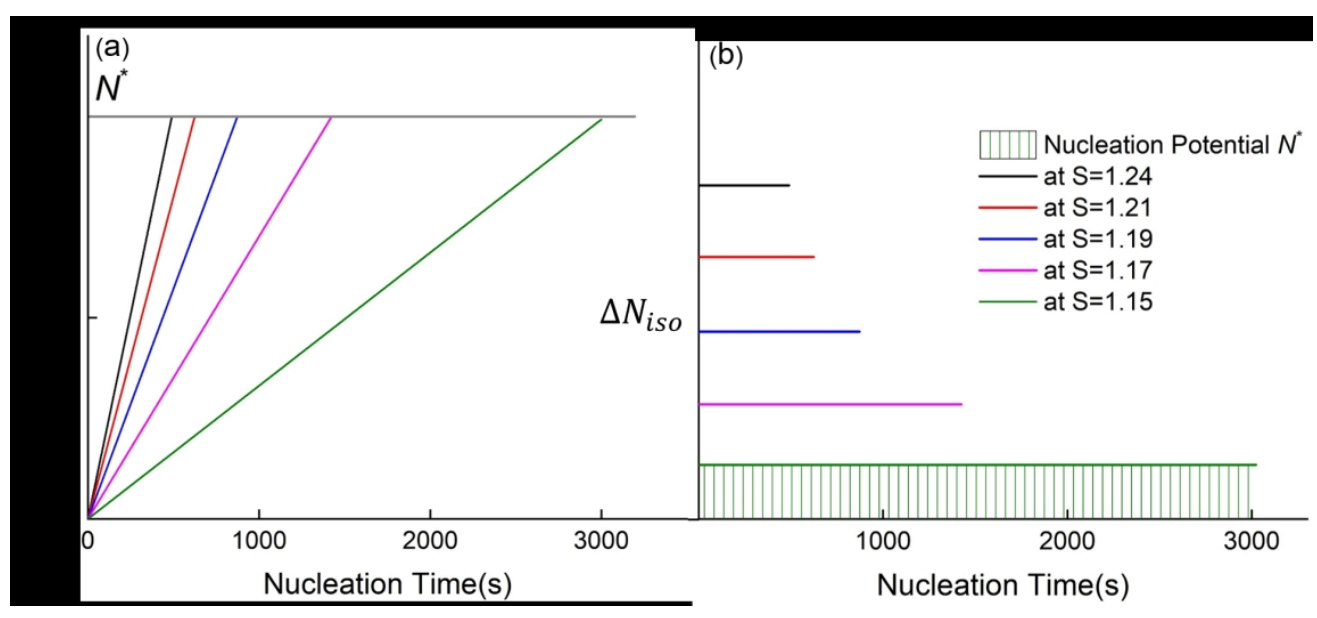

$325 \times 147 \mathrm{~mm}(150 \times 150$ DPI $)$ 


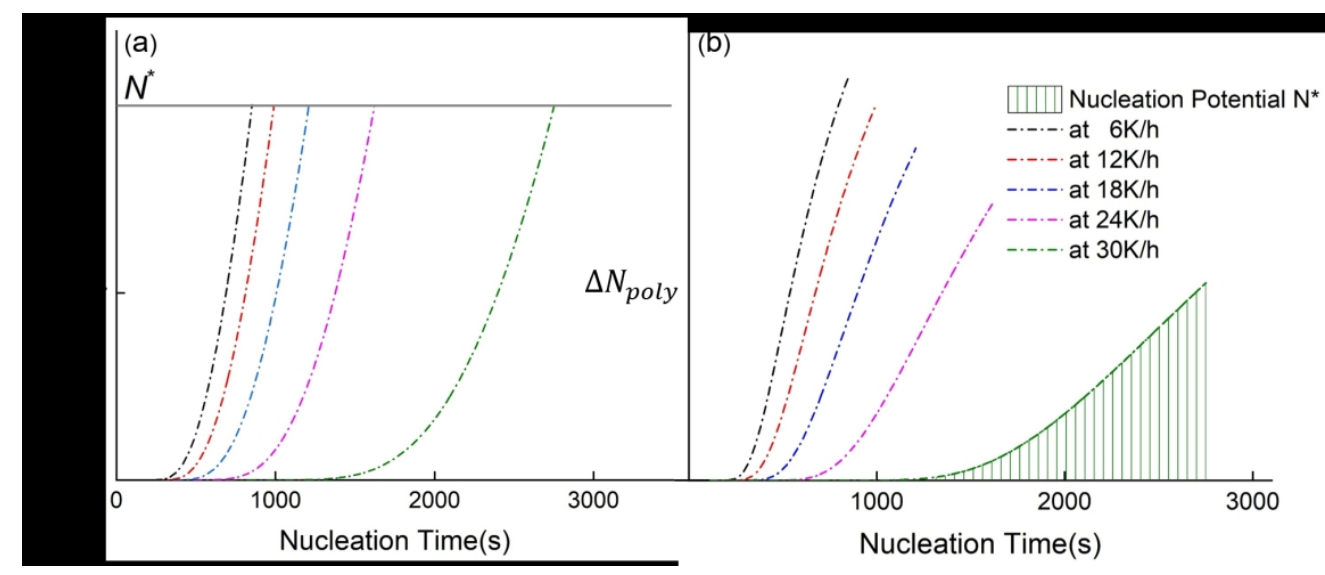

$336 \times 142 \mathrm{~mm}(150 \times 150$ DPI $)$ 


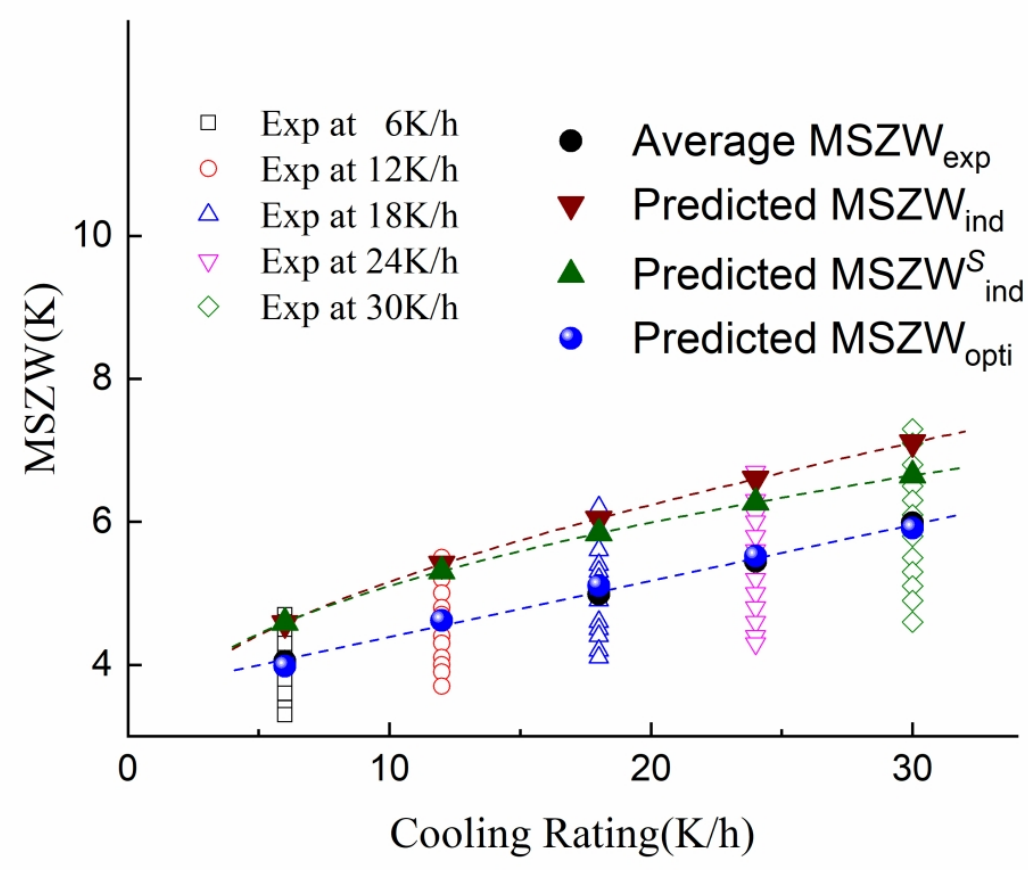

$272 \times 208 \mathrm{~mm}(300 \times 300$ DPI $)$ 


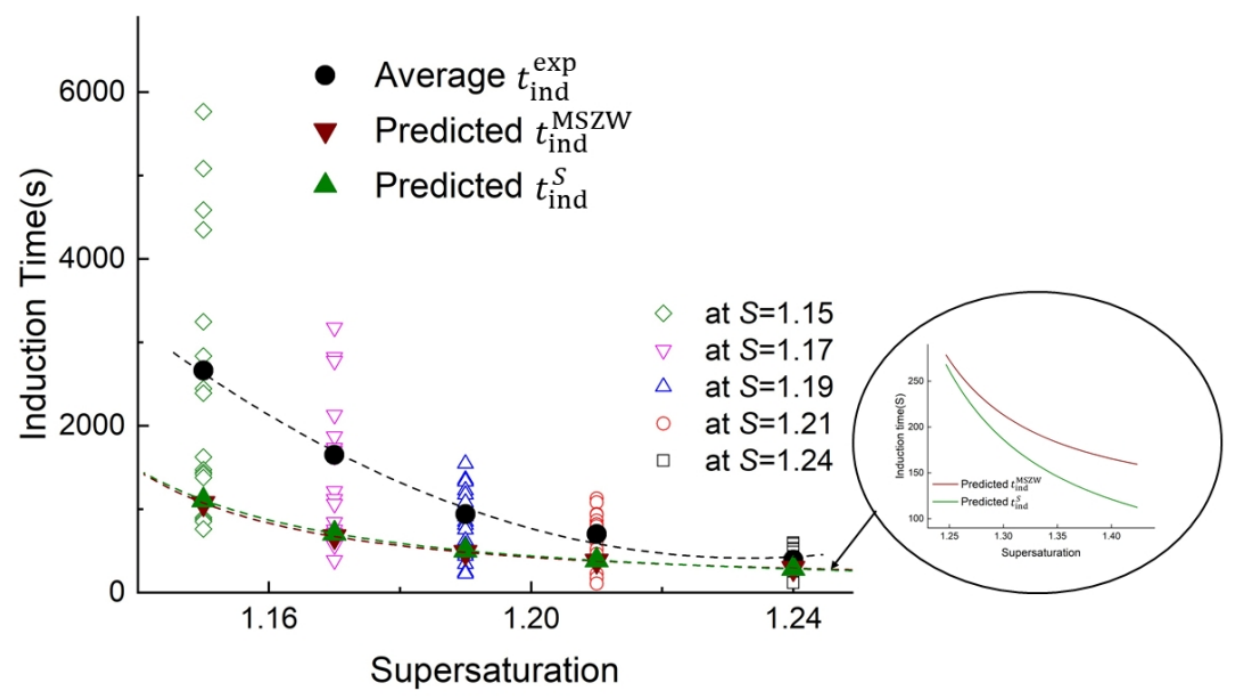

$338 \times 190 \mathrm{~mm}(96 \times 96$ DPI) 